\title{
BiodegradaçÃo do Diclosulam POR Bactérias Isoladas de Solos Cultivados COM SOJA ${ }^{1}$
}

\author{
Diclosulam Biodegration by Bacteria Isolated from Soybean Cultivated Soils
}

RODRIGUES, N.R. ${ }^{2}$ ANDRIETTA, M.G.S. ${ }^{3}$ ANDRIETTA, S.R. ${ }^{4}$ e SANTOS, P.E.R. ${ }^{5}$

\begin{abstract}
RESUMO - Este trabalho teve como objetivo avaliar a capacidade de degradação do herbicida diclosulam por bactérias. Essas bactérias foram isoladas de solos procedentes de três importantes regiões de cultivo de soja do Brasil, as quais receberam a aplicação do herbicida diclosulam. Os testes foram conduzidos em shaker, sendo utilizado um meio de cultivo sintético. As características avaliadas foram: massa de glicose e diclosulam consumidos, velocidade de degradação do diclosulam e massa celular produzida. Embora todas elas tenham sido capazes de utilizar o diclosulam, os resultados indicaram que Klebsiella sp. foi mais eficiente e promissora para ser utilizada na biorremediação de áreas contaminadas com esse composto.
\end{abstract}

Palavras-chave: biorremediação, cometabolismo, diclosulam, herbicida.

ABSTRACT - This work aimed to evaluate diclosulam degradation by ten bacteria strains isolated from soils collected from three important soybean cultivation regions in Brazil. The tests were conducted in a shaker using a synthetic medium. The evaluated parameters were: glucose mass and diclosulam consumed, diclosulam degradation rate, and cell mass produced. Although all the 10 bacteria strains could use diclosulam, the results showed that the bacterium strain Klebsiella $s p$. was the most efficient and promising for bioremediation of diclosulam-contaminated areas.

Keywords: bioremediation, cometabolism, diclosulam, herbicide.

\section{INTRODUÇÃO}

Para atender à enorme demanda por alimentos, surgiram os agroecossistemas e monocultivos. Essas novas modalidades de produção agrícola favoreceram o aparecimento de pragas, doenças, ervas daninhas e microrganismos, decorrentes do desequilibrio que atingiu essas populações. Para controlar as doenças provocadas nas lavouras em função dessa nova realidade surgem os pesticidas, que, se por um lado são capazes de controlar essas doenças, por outro, causam extensos prejuízos ao ambiente solo. Existem 600 ingredientes ativos, utilizados na formulação de pesticidas, registrados para uso na agricultura (Richard, 1998). O Brasil, como um país agricultor, aparece como o oitavo maior consumidor de pesticida mundial (Galli et al., 2006). Embora essa realidade seja irreversivel, há uma preocupação geral em desenvolver formas eficientes de remover os residuos desses pesticidas do meio ambiente, uma vez que eles não estão restritos ao solo e circulam

1 Recebido para publicação em 24.9.2009 e na forma revisada em 15.6.2010.

2 Pesquisador, Universidade Estadual de Campinas - CPQBA-UNICAMP. Caixa Postal 6171, 13081-970, Campinas, SP, $<$ nadia@cpqba.unicamp.br>; ${ }^{3}$ Pesquisador, Universidade Estadual de Campinas - CPQBA-UNICAMP, Caixa Postal 6171, 13081-970, Campinas, SP, <stupielo@cpqba.unicamp.br>; ${ }^{4}$ Pesquisador, Biotecnologia em Bioprocessos, Av. José Rocha Bonfim, 214, BL H, SL 216 - 13100-000 - Campinas, SP, <s.andrietta@terra.com.br>; ${ }^{5}$ Farmacêutico, Universidade Estadual de Campinas CPQBA-UNICAMP, Caixa Postal 6171, 13081-970, Campinas, SP, <paulo.rubbo@cpqba.unicamp.br>. 
por todos os ambientes da Terra, seja no próprio alimento ou pela contaminação das águas.

O Brasil é o segundo maior produtor mundial de soja. Na safra 2008/2009 foram produzidos 57,1 milhões de toneladas do grão, em uma área de plantio de 30,2 milhões de hectares (Embrapa, 2009). Entre os 15 diferentes princípios ativos de herbicidas utilizados nas lavouras da soja brasileira inclui-se o diclosulam (Balcewicz, 2008). Trabalhos recentes vêm mostrando a ação desse herbicida tanto na soja como nos organismos não alvo (Leite et al., 2000; Brighenti et al., 2002; Correia et al., 2006; Timossi \& Durigan, 2006; Constantin et al., 2007; F. Neto et al., 2009).

O diclosulam (N-[2,6-diclorofenil]-5-etoxi7 -fluoro $(1,2,4)$ triazolo- $[1,5 \mathrm{c}]$-piramidina-2sulfonamida) é um herbicida do grupo químico triazolo pirimidina sulfonanilidas indicado para o controle de dicotiledôneas em pré-semeadura incorporada ou em pré-emergência na cultura de soja. Esse composto atua inibindo a enzima acetolactato sintase (ALS), a qual é essencial para a sintese de aminoácidos valina, leucina e isoleucina (Rodrigues \& Almeida, 1998). $\mathrm{O}$ diclosulam atende às propriedades atualmente esperadas para um pesticida. Segundo Monteiro (2001), essas propriedades incluem a sua pronta degradabilidade, eficiência em doses baixas, especificidade e baixa toxicidade para os organismos não alvo. Gupta (2007) relata a baixa toxidez do diclosulam. Segundo Zabik et al. (2001), a degradação do diclosulam em solos americanos (Mississipi, North Carolina, Illinois e Georgia) foi rápida: a meia-vida variou de 13 a 43 dias, em função das localidades estudadas.

A atividade microbiana é o fator preponderante na determinação da velocidade e extensão da degradação dos pesticidas no solo (Silva, 2001). As condições do ambiente que favorecem o desenvolvimento microbiano no solo são as mesmas que favorecem a degradação de pesticidas: temperatura, umidade e aeração (Monteiro, 2001). A degradação de uma molécula por agentes biológicos é conhecida como biodegradação (Alexander, 1999). Os microrganismos do solo, principalmente bactérias e fungos, têm sido relatados como os principais degradadores de pesticidas (Monteiro, 2001). Os microrganismos exibem duas estratégias ecológicas para a assimilação do substrato ou metabolismo: mineralização e cometabolismo. Na primeira, o substrato absorvido é quebrado em pequenas moléculas, as quais são posteriormente metabolizadas em rotas que geram energia. Nesse caso, a biomassa microbiana aumenta às expensas do substrato. Ao contrário da mineralização, no cometabolismo não há geração de energia. O resultado é um metabólito que poderá ser degradado posteriormente ou poderá ligar-se à matriz orgânica.

Há evidências de que para alguns compostos orgânicos a biodegradação acelerada ocorre após uma alta pressão seletiva durante o período de incubação. Às vezes, uma simples dose do pesticida leva a aumento significante na taxa de degradação da aplicação subsequente (Silva, 2001). Karpouzas et al. (2001), estudando a degradação de carbofuran, constataram que solos de áreas sem histórico de aplicação do pesticida foram caracterizadas por uma pequena fase lag, seguida de rápida degradação. Na aplicação subsequente houve rápida degradação do composto sem aparecimento da fase lag; portanto, uma simples aplicação do carbofuran ativou a microbiota dos solos para a biodegradação acelerada do produto.

$\mathrm{O}$ isolamento de microrganismos do solo onde se fez uso da molécula que se pretende biodegradar é uma estratégia interessante, uma vez que ocorreu nesses ambientes uma seleção natural dos microrganismos habitantes, decorrente das repetidas aplicações da molécula. Nesse contexto, este trabalho teve como objetivo avaliar a capacidade de degradação do diclosulam por 10 diferentes bactérias isoladas de solos cultivados com soja e tratados com diclosulam.

\section{MATERIAL E MÉTODOS}

O herbicida avaliado foi o diclosulam (Spider 840 GRDA $^{\circledR}$ ). Foram utilizadas 10 diferentes linhagens de bactérias, todas isoladas de solos cultivados com soja e que utilizaram diclosulam como herbicida. Dessas, quatro linhagens eram provenientes da região de Uberlândia (MG), três da região de Londrina (PR) e três da região de Rondonópolis (MT). A classificação textural dos solos foi franco-arenosa, 
muito argilosa e argila, respectivamente, para as regiões citadas. As linhagens foram identificadas da seguinte maneira: UL1, UL2, UL3 e UL4 (Uberlândia), LL1, LL2 e LL3 (Londrina) e RL1, RL2 e RL3 (Rondonópolis).

A linhagem mais promissora para ser utilizada para degradar o diclosulam foi identificada utilizando sequenciamento e análise filogenética de fragmentos do gene rRNA 16S (Kimura, 1980).

Os ensaios foram conduzidos em agitador (shaker), em triplicata, em erlenmeyers de $250 \mathrm{~mL}$ de capacidade, contendo $90 \mathrm{~mL}$ de meio de fermentação, com a seguinte composição em g L ${ }^{-1}: \mathrm{KH}_{2} \mathrm{PO}_{4}(0,36), \mathrm{K}_{2} \mathrm{HPO}_{4}(1,40), \mathrm{MgSO}_{4}$ $(0,25), \mathrm{KCl}(0,02) \mathrm{NaCl}(0,20), \mathrm{NH}_{4} \mathrm{Cl}(5)$, glicose (20), extrato de levedura DIFCO (5) e $100 \mu \mathrm{g} \mathrm{mL}^{-1}$ de diclosulam. O inóculo foi produzido pela suspensão em água estéril dos microrganismos crescidos em meio King's B (Peptona $10 \mathrm{~g} \mathrm{~L}^{-1} ; \mathrm{KH}_{2} \mathrm{PO}_{4}=1,5 \mathrm{~g} \mathrm{~L}^{-1} ; \mathrm{MgSO}_{4}=1,5 \mathrm{~g} \mathrm{~L}^{-1}$; glicerol $=10 \mathrm{~g} \mathrm{~L}^{-1}$; ágar $=20 \mathrm{~g} \mathrm{~L}^{-1}$ ) por 24 horas a $32{ }^{\circ} \mathrm{C}$. As células em suspensão foram adicionadas em volumes iguais a $10 \mathrm{~mL}$ nos frascos de fermentação. Os microrganismos foram incubados até 72 horas, $32{ }^{\circ} \mathrm{C}$ e $150 \mathrm{rpm}$.

Resultados preliminares mostraram que os microrganismos foram capazes de apresentar crescimento em até $100 \mu \mathrm{g} \mathrm{mL} \mathrm{m}^{-1}$ de diclosulam.

Amostras foram retiradas nos tempos de 0, 24, 48 e 72 horas, para determinação de massa seca, concentração de diclosulam e concentração de glicose. As amostras foram analisadas em relação a massa celular, glicose e diclosulam.

\section{Parâmetros avaliados}

Foram utilizados os seguintes parâmetros: massa celular produzida em g $(\mathrm{MCP}=$ massa de células no final da fermentação - massa de células do inóculo); massa de glicose consumida em g (MGC = massa inicial de glicose massa final de glicose); massa de diclosulam degradado em g $(\mathrm{MDD}=$ massa de diclosulam inicial - massa de diclosulam final), rendimento em célula em $\mathrm{g} \mathrm{Y}_{\mathrm{X} / \mathrm{S}}$ = massa de células produzidas/massa de glicose consumida); velocidade de degradação de diclosulam em $\mathrm{mg} \mathrm{h}^{-1}$ (VDD = massa de diclosulam degradada/ tempo do ensaio); e degradação específica de diclosulam em g de diclosulam/g células (DED = massa de diclosulam degradada/massa de células produzidas). Todos esses parâmetros foram obtidos a partir de balanço de massa.

\section{Metodologia analítica}

As análises de resíduos de diclosulam foram realizadas em um sistema de cromatografia líquida de alta eficiência contendo uma bomba isocrática - HP 1500; detector Shimadzu UV $(\lambda=254 \eta \mathrm{m})$; coluna analitica Phenomenex, Luna $\mathrm{C} 18,5 \mu \mathrm{m}$; fase móvel: acetonitrila: água 90:10 e 1\% de ácido acético com fluxo de $0,5 \mathrm{~mL} \mathrm{~min}{ }^{-1}$; e padrão diclosulam com $97 \%$ de pureza.

As análises de glicose foram realizadas em um sistema de cromatografia líquida de alta eficiência Dionex com detector de amperometria pulsada - eletrodo de ouro e uma coluna analítica carboPac PA-1; fase móvel: hidróxido de sódio $150 \mathrm{mM}$ com fluxo de 1,0 mL $\mathrm{min}^{-1}$; e padrão de glicose com $99,5 \%$ de pureza.

Para determinação da massa seca, retiraram-se alíquotas de $20 \mathrm{~mL}$ do fermentado centrifugado (4.500 rpm, por 10 minutos). O fermentado centrifugado foi lavado com água destilada e recentrifugado por três vezes. Em seguida, foi transferido para uma placa previamente tarada e levado para estufa a $60^{\circ} \mathrm{C}$ até peso constante. $\mathrm{O}$ valor da massa seca foi obtido pela diferença entre os pesos inicial e final da placa.

Os dados foram tratados estatisticamente. Para isso, utilizou-se o programa Origin 8 (Origin Lab Corporation).

\section{RESULTADOS E DISCUSSÃO}

Todas as 10 linhagens estudadas foram capazes de crescer na presença do diclosulam, utilizando de alguma maneira esse composto. A capacidade apresentada por todas as bactérias de crescer na presença dessa molécula reforça os resultados obtidos por Lavorenti et al. (2003). Esses pesquisadores estudaram a ação do diclosulam na atividade microbiana do solo e concluíram que essa molécula não alterou essa atividade de solos provenientes de qualquer sistema de manejo. A baixa 
toxicidade associada a essa molécula (Gupta, 2007) fica também evidenciada nos resultados obtidos neste trabalho.

O diclosulam foi consumido simultaneamente ao consumo da glicose, indicando que ele não foi utilizado como fonte de carbono, uma vez que o metabolismo bacteriano preconiza o fenômeno da diauxia, que é o esgotamento total de uma fonte de carbono para o início da utilização de outra fonte de carbono disponivel (Schlegel, 1992).

Na Figura 1 são mostrados os perfis de concentração de glicose, massa celular e diclosulam em função do tempo de fermentação. Observa-se que eles foram diferentes para cada uma das quatro linhagens isoladas da região de Uberlândia. No entanto, para todas as linhagens, constatou-se que o diclosulam foi consumido de forma acentuada nas primeiras 24 horas de ensaio, ficando praticamente constante após esse tempo.

Pelos resultados da Figura 2, observa-se que o comportamento das linhagens LL2 e LL3 foi semelhante ao das linhagens da região de Uberlândia. A linhagem LL1 mostrou comportamento diferenciado: o maior crescimento
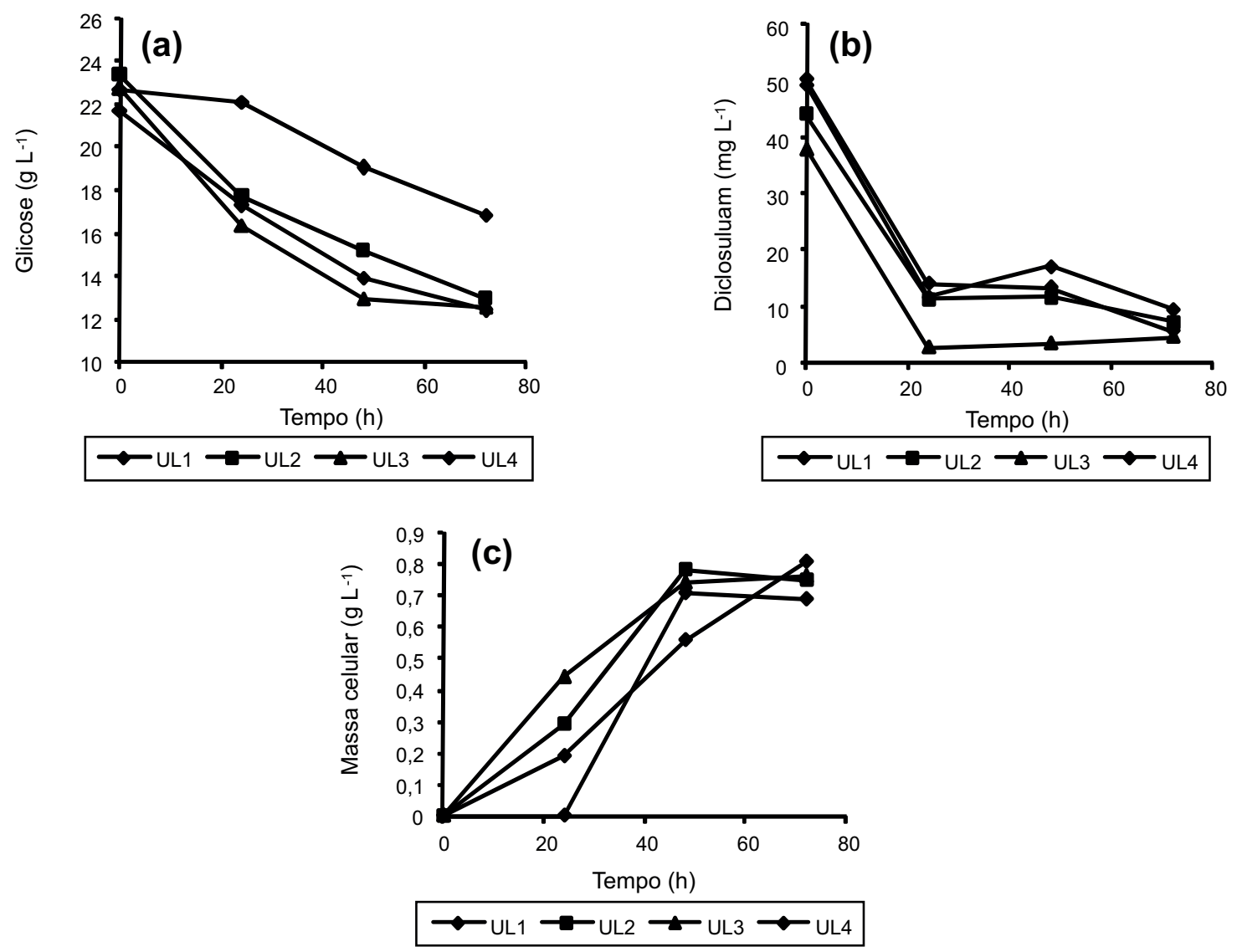

\begin{tabular}{|c|c|c|c|c|c|c|c|c|c|c|c|}
\hline & \multicolumn{4}{|c|}{$\begin{array}{l}\text { Desvio da média-glicose } \\
\left(\mathrm{g} \mathrm{L}^{-1}\right)\end{array}$} & \multicolumn{4}{|c|}{$\begin{array}{l}\text { Desvio da média-diclosulam } \\
\left(\mathrm{g} \mathrm{L}^{-1}\right)\end{array}$} & \multicolumn{3}{|c|}{$\begin{array}{l}\text { Desvio da média-massa celular } \\
\left(\mathrm{g} \mathrm{L}^{-1}\right)\end{array}$} \\
\hline & $0 \mathrm{~h}$ & $24 \mathrm{~h}$ & $48 \mathrm{~h}$ & $72 \mathrm{~h}$ & $0 \mathrm{~h}$ & $24 \mathrm{~h}$ & $48 \mathrm{~h}$ & $72 \mathrm{~h}$ & $24 \mathrm{~h}$ & $48 \mathrm{~h}$ & $72 \mathrm{~h}$ \\
\hline UL1 & $21,8 \pm 1,3$ & $17,3 \pm 7,3$ & $13,9 \pm 6,7$ & $12,4 \pm 5,1$ & $, 4 \pm 8,4$ & $14,1 \pm 3,6$ & $13,4 \pm 4,7$ & $5,4 \pm 1$ & 0 & $71 \pm 0,24$ & $0,69 \pm 0,69$ \\
\hline UL2 & 5,7 & $17,8 \pm 3,3$ & $15,2 \pm 2,3$ & $13,0 \pm 2,6$ & $44,1 \pm 15,8$ & $11,5 \pm 3,3$ & $11,9 \pm 2,9$ & $0,8 \pm 0,18$ & $0,29 \pm 0,11$ & $0,78 \pm 0,21$ & $0,75 \pm 0,18$ \\
\hline $\begin{array}{l}\text { UL3 } \\
\end{array}$ & $8 \pm 7,3$ & $16,4 \pm 4,4$ & $13,0 \pm 3,5$ & $12,6 \pm 5,6$ & $38,0 \pm 11,5$ & $2,8 \pm 0,7$ & $3,5 \pm 1,1$ & $4,7 \pm 1,1$ & $0,44 \pm 0,17$ & $0,74 \pm 0,27$ & $\overline{0,76 \pm 0,30}$ \\
\hline$\overline{\mathrm{UL} 4}$ & $22,7 \pm 9,0$ & $22,2 \pm 1,2$ & $19,1 \pm 3,2$ & $16,9 \pm 6,2$ & $49,4 \pm 12,2$ & $11,7 \pm 5,3$ & $17,1 \pm 1,9$ & $9,5 \pm 3,4$ & $0,19 \pm 0,06$ & $0,56 \pm 0,21$ & $0,81 \pm 0,35$ \\
\hline
\end{tabular}

Figura 1 - Perfís da concentração de glicose (1a), diclosulam (1b) e massa celular (1c) em função do tempo de fermentação para as linhagens isoladas, em solo da localidade de Uberlândia submetido ao cultivo de soja e posterior aplicação do referido herbicida. Estão tabelados os desvios da média para os parâmetros estudados. 
celular com maior consumo de glicose degradou menor quantidade de diclosulam, quando comparada às outras linhagens.

Os resultados para as bactérias RL2 e RL3 (Figura 3) foram semelhantes entre si, assim como coincidentes com os obtidos para as outras bactérias estudadas. Entretanto, para a linhagem RL1 foi observado comportamento diferenciado. Esta bactéria consumiu totalmente a glicose em 24 horas, atingindo o seu pico de crescimento nesse mesmo período. A partir do tempo de 24 horas, a massa celular decresceu. Essa linhagem, embora tenha utilizado o diclosulam, o fez em concentrações menores quando comparada à de outras bactérias.

O decréscimo da massa celular pode ser atribuído à morte celular (lise), o que também explica a ausência do consumo de diclosulam a partir desse tempo.

Embora todas as linhagens tenham sido capazes de utilizar o diclosulam, os dados mostram variação nesse consumo entre as bactérias estudadas (Tabela 1). A quantidade de diclosulam consumida no final do ensaio variou entre 1,10 mg (RL3) e 9,60 mg (RL2).
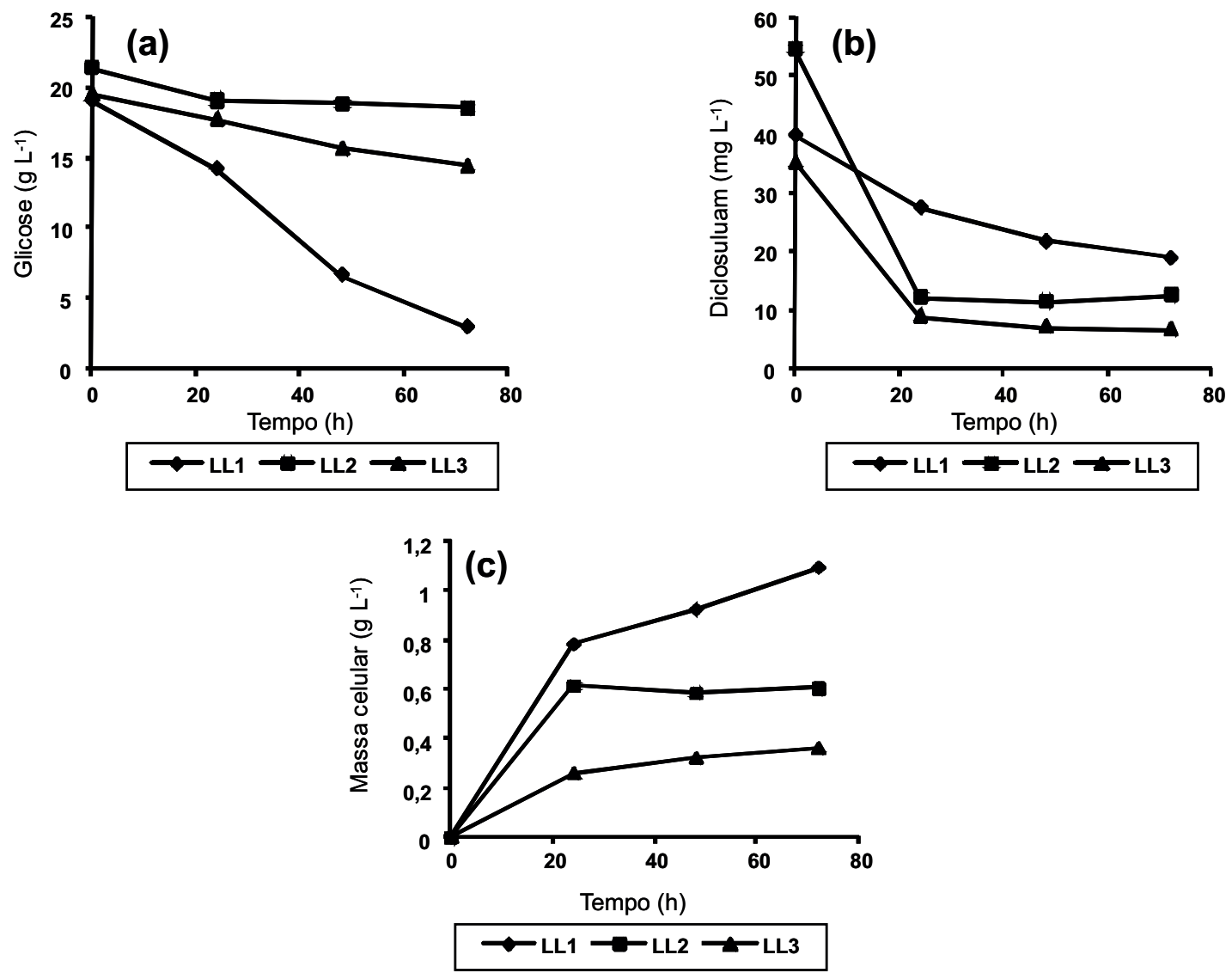

\begin{tabular}{|l|c|c|c|c|c|c|c|c|c|c|c|}
\hline & \multicolumn{4}{|c|}{$\begin{array}{c}\text { Desvio da média-glicose } \\
\left(\mathrm{g} \mathrm{L}^{-1}\right)\end{array}$} & \multicolumn{3}{c|}{$\begin{array}{c}\text { Desvio da média-diclosulam } \\
\left(\mathrm{g} \mathrm{L}^{-1}\right)\end{array}$} & \multicolumn{3}{c|}{$\begin{array}{c}\text { Desvio da média-massa celular } \\
\left(\mathrm{g} \mathrm{L}^{-1}\right)\end{array}$} \\
\cline { 2 - 14 } & $0 \mathrm{~h}$ & $24 \mathrm{~h}$ & $48 \mathrm{~h}$ & $72 \mathrm{~h}$ & $0 \mathrm{~h}$ & $24 \mathrm{~h}$ & $48 \mathrm{~h}$ & $72 \mathrm{~h}$ & $24 \mathrm{~h}$ & $48 \mathrm{~h}$ & $72 \mathrm{~h}$ \\
\hline LL1 & $19,2 \pm 8,6$ & $14,3 \pm 6,4$ & $6,7 \pm 2,3$ & $3,0 \pm 51,1$ & $40,0 \pm 14,0$ & $27,7 \pm 2,2$ & $21,9 \pm 5,33$ & $19,1 \pm 5,3$ & $0,78 \pm 0,35$ & $0,92 \pm 0,29$ & $1,09 \pm 0,20$ \\
\hline LL2 & $21,5 \pm 6,8$ & $19,1 \pm 8,3$ & $18,9 \pm 3,8$ & $18,6 \pm 3,0$ & $54,8 \pm 7,3$ & $12,3 \pm 4,7$ & $11,6 \pm 2,9$ & $12,7 \pm 3,9$ & $0,61 \pm 0,24$ & $0,58 \pm 0,15$ & $0,6 \pm 0,04$ \\
\hline LL3 & $19,6 \pm 8,1$ & $17,8 \pm 3,3$ & $15,7 \pm 2,8$ & $14,5 \pm 2,6$ & $35,5 \pm 8,6$ & $9,1 \pm 3,4$ & $7,4 \pm 1,4$ & $6,9 \pm 2,6$ & $0,26 \pm 0,09$ & $0,32 \pm 0,12$ & $0,36 \pm 0,12$ \\
\hline
\end{tabular}

Figura 2 - Perfis da concentração de glicose (a), diclosulam (b) e massa celular (c) em função do tempo de fermentação para as linhagens isoladas, em solo da localidade de Londrina submetido ao cultivo de soja e posterior aplicação do referido herbicida. Estão tabelados os desvios da média para os parâmetros estudados. 

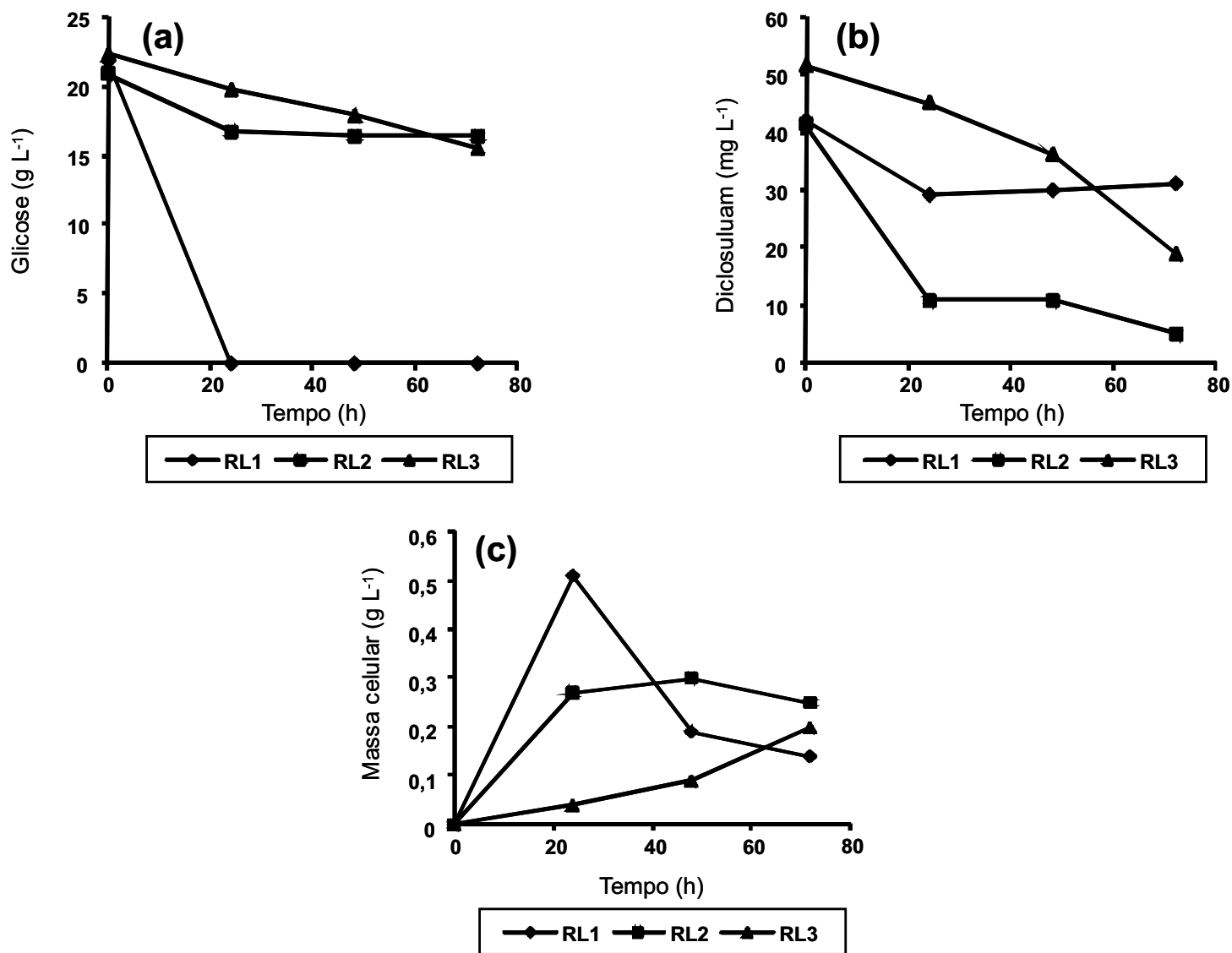

\begin{tabular}{|l|c|c|c|c|c|c|c|c|c|c|c|}
\hline & \multicolumn{4}{|c|}{$\begin{array}{c}\text { Desvio da média-glicose } \\
\left(\mathrm{g} \mathrm{L}^{-1}\right)\end{array}$} & \multicolumn{3}{c|}{ Desvio da média-diclosulam } & \multicolumn{3}{c|}{ Desvio da média-massa celular } \\
$\left(\mathrm{g} \mathrm{L}^{-1}\right)$ & & & \multicolumn{3}{c|}{$\left(\mathrm{g} \mathrm{L}^{-1}\right)$} \\
\cline { 2 - 14 } & $0 \mathrm{~h}$ & $24 \mathrm{~h}$ & $48 \mathrm{~h}$ & $72 \mathrm{~h}$ & $0 \mathrm{~h}$ & $24 \mathrm{~h}$ & $48 \mathrm{~h}$ & $72 \mathrm{~h}$ & $24 \mathrm{~h}$ & $48 \mathrm{~h}$ & $72 \mathrm{~h}$ \\
\hline RL1 & $21,9 \pm 8,2$ & 0 & 0 & 0 & $42,2 \pm 10,4$ & $29,3 \pm 7,0$ & $30,1 \pm 10,9$ & $31,3 \pm 14,3$ & $0,51 \pm 0,17$ & $0,27 \pm 0,01$ & $0,04 \pm 0,01$ \\
\hline RL2 & $21,0 \pm 5,3$ & $16,7 \pm 6,8$ & $16,5 \pm 7,7$ & $16,5 \pm 0,8$ & $41,6 \pm 17,5$ & $11,0 \pm 4,7$ & $11,0 \pm 0,5$ & $5,3 \pm 1,0$ & $0,19 \pm 0,06$ & $0,30 \pm 0,11$ & $0,09 \pm 0,04$ \\
\hline RL3 & $22,4 \pm 0,7$ & $19,9 \pm 6,2$ & $17,9 \pm 6,9$ & $15,5 \pm 5,9$ & $51,7 \pm 21,3$ & $45,3 \pm 10,0$ & $36,4 \pm 15,5$ & $19,2 \pm 5,3$ & $0,14 \pm 0,05$ & $0,25 \pm 0,04$ & $0,20 \pm 0,03$ \\
\hline
\end{tabular}

Figura 3 - Perfis da concentração de glicose (3a), diclosulam (3b) e massa celular (3c) em função do tempo de fermentação para as linhagens isoladas, em solo da localidade de Rondonópolis submetido ao cultivo de soja e posterior aplicação do referido herbicida. Estão tabelados os desvios da média para os parâmetros estudados.

Em relação ao crescimento celular, a variação foi de 0,03 (UL1) a 0,14g (LL1). A linhagem que consumiu a maior quantidade de glicose foi a RL1 (4,10 g), e a que menos consumiu, a LL3 $(0,29 \mathrm{~g})$. Não foi possivel observar nenhuma relação entre a quantidade de diclosulam consumido e a massa de microrganismo ou mesmo em relação ao consumo da glicose.

O uso do parâmetro DED como fator de seleção para a escolha do microrganismo deve ser considerado, uma vez que, quanto maior esse parâmetro, menor a quantidade de células necessárias para degradar uma dada massa do diclosulam. Se esse for o critério adotado para a escolha, as linhagens UL2, RL2, UL1 e UL3 são os isolados que se apresentam mais adequados.

Outro parâmetro importante diz respeito à massa de células produzidas (MCP). Considerando que esses microrganismos poderão ser cultivados em grandes volumes para posterior aplicação em áreas a serem biorremediadas, a obtenção de altas concentrações de células passa a ser uma vantagem de caráter tecnológico. As linhagens LL1, LL2, RL1 e UL4 são as que mais se destacam nesse parâmetro. 
Tabela 1 - Valores dos parâmetros MCP (massa de células produzidas), MGC (massa de glicose consumida), MDD (massa de diclosulam degradado), $\mathrm{Y}_{\mathrm{x/S}}$ (rendimento em célula), $\mathrm{VCD}$ (velocidade de degradação do diclosulam) e DED (degradação específica do diclosulam) para as 10 linhagens estudadas. \pm corresponde à variação estatística

\begin{tabular}{|c|c|c|c|c|c|c|}
\hline Parâmetro & $\begin{array}{c}\mathrm{MCP} \\
(\mathrm{g})\end{array}$ & $\begin{array}{c}\mathrm{MGC} \\
(\mathrm{g})\end{array}$ & $\begin{array}{c}\mathrm{MDD} \\
(\mathrm{mg})\end{array}$ & $\begin{array}{c}\mathrm{Y}_{\mathrm{X} / \mathrm{s}} \\
\left(\mathrm{g} \mathrm{g}^{-1}\right)\end{array}$ & $\begin{array}{c}\text { VCD } \\
\left(\mathrm{mg} \mathrm{h}^{-1}\right)\end{array}$ & $\begin{array}{c}\text { DED } \\
\left(\mathrm{g} \mathrm{g}^{-1} \mathrm{MS}\right)\end{array}$ \\
\hline UL1 & $0,029 \pm 0,012$ & $0,78 \pm 0,39$ & $4,80 \pm 1,40$ & $0,040 \pm 0,078$ & $0,200 \pm 0,078$ & $0,163 \pm 0,037$ \\
\hline UL2 & $0,028 \pm 0,016$ & $0,75 \pm 0,35$ & $5,00 \pm 1,65$ & $0,037 \pm 0,078$ & $0,209 \pm 0,081$ & $0,181 \pm 0,054$ \\
\hline UL3 & $0,050 \pm 0,026$ & $3,27 \pm 1,40$ & $7,10 \pm 1,11$ & $0,016 \pm 0,078$ & $0,297 \pm 0,115$ & $0,144 \pm 0,054$ \\
\hline UL4 & $0,086 \pm 0,029$ & $0,82 \pm 0,34$ & $8,40 \pm 1,98$ & $0,104 \pm 0,078$ & $0,350 \pm 0,130$ & $0,098 \pm 0,034$ \\
\hline LL1 & $0,140 \pm 0,070$ & $0,91 \pm 0,39$ & $1,50 \pm 1,04$ & $0,153 \pm 0,078$ & $0,064 \pm 0,019$ & $0,011 \pm 0,004$ \\
\hline LL2 & $0,111 \pm 0,029$ & $0,48 \pm 0,07$ & $5,70 \pm 1,77$ & $0,237 \pm 0,078$ & $0,239 \pm 0,045$ & $0,051 \pm 0,014$ \\
\hline LL3 & $0,044 \pm 0,021$ & $0,29 \pm 0,10$ & $4,20 \pm 1,28$ & $0,158 \pm 0,078$ & $0,174 \pm 0,082$ & $0,098 \pm 0,065$ \\
\hline RL1 & $0,089 \pm 0,030$ & $4,10 \pm 1,16$ & $2,60 \pm 0,76$ & $0,022 \pm 0,078$ & $0,108 \pm 0,045$ & $0,030 \pm 0,013$ \\
\hline RL2 & $0,042 \pm 0,014$ & $0,90 \pm 0,24$ & $9,60 \pm 2,43$ & $0,047 \pm 0,078$ & $0,298 \pm 0,068$ & $0,176 \pm 0,043$ \\
\hline RL3 & $0,021 \pm 0,014$ & $0,35 \pm 0,314$ & $1,10 \pm 0,63$ & $0,082 \pm 0,078$ & $0,047 \pm 0,018$ & $0,079 \pm 0,021$ \\
\hline
\end{tabular}

A linhagem UL3, identificada como Klebsiella sp., apresenta-se, entre as linhagens estudadas, como a mais promissora para ser cultivada em grande escala. Embora ela não tenha sido relacionada em primeiro lugar para os parâmetros quando se avaliou de forma isolada, quando se trata do desempenho global, é ela que se destaca, pois foi capaz de degradar significativa quantidade de diclosulam (3,27 mg), foi eficiente na produção de células $(0,05 \mathrm{~g})$ e apresentou um DED considerado adequado.

Mesmo de formas distintas, todos os isolados foram capazes de utilizar de alguma maneira o diclosulam. Todos eles foram também capazes de crescer na presença desse composto.

Nenhuma das bactérias envolvidas neste trabalho teve o diclosulam como fonte de carbono, uma vez que o composto foi utilizado simultaneamente ao consumo da glicose. Os resultados confirmam que o diclosulam é um produto facilmente degradado.

\section{LITERATURA CITADA}

ALEXANDER, M. Biodegradation of environmental concern. Science, v. 211, p. 132-138, 1981.

ALEXANDER, M. Effect of chemical structure on biodegradation in biodegradation and bioremediation. 2.ed. New York: Academic Press, 1999. p.
ANDERSON, J. P. E. Herbicide degradation in soil: influence of microbial biomass. Soil Biol. Biochem., v. 13, n. 5 , p. $483-489,1984$.

BALCEWICZ, L. C. Evolução das quantidades consumidas dos principais herbicidas para a cultura da soja (Glycine max (L.) Merrill) no estado do Mato Grosso, Paraná, Rio Grande do Sul e Brasil no período de 2000-2005. In: CONGRESSO DA SOCIEDADE BRASILEIRA DE ECONOMIA, ADMINISTRAÇÃO E SOCIOLOGIA RURAL - SOBER, 46., 2008, Rio Branco. Anais... Rio Branco, 2008.

BRIGHENTI, A. M. et al. Persistência e fitotoxicidade de herbicidas aplicados na soja sobre girassol em sucessão. Pesq. Agropec. Bras., v. 37, n. 4, p. 559-565, 2002.

CARDOSO, E. J. B. N.; FREITAS, S. S. A. Rizosfera. In: CARDOSO, E. J. B. N. et al. Microbiologia do solo. Campinas: Sociedade Brasileira de Ciência do Solo, 1992 p. 41-57.

CONSTANTIN, J. et al. Estimativa do período que antecede a interferência de plantas daninhas na cultura de soja, var. coodetec 202, por meio de testemunhas duplas. Planta Daninha, v. 25, n. 2, p. 231-237, 2007.

CORREIA, N. M.; DURIGAN, J. C.; MELO, W. J. Envelhecimento de resíduos vegetais sobre o solo e os reflexos na eficácia de herbicidas aplicados em pré-emergência. Bragantia, v. 66, n. 1, p. 101-110, 2007

DOW AGROSCIENCE, 2009. Disponível em: <http:// www.dowagro.com/br/fichas/>. Acesso em: 20 abr. 2009

Planta Daninha, Viçosa-MG, v. 28, n. 2, p. 393-400, 2010 
EMBRESA BRASILEIRA DE PESQUISA

AGROPECUÁRIA - EMBRAPA. 2009. Disponível em :

$<$ http://www. embrapa.com.br>. Acesso em: 17 nov. 2009

GALLI, A. et al. Utilização de técnicas eletroanalíticas na determinação de pesticidas em alimentos. Química Nova, v. 29, n. 1, p. $1-14,2006$.

GUPTA, P. K. Toxicity of herbicides. In: GUPTA, R. C. Veterinary toxicology. USA, KY: Murray State University, 2007. p. 567-586.

IUPAC-GLOBAL AVAILABILITY OF INFORMATION ON AGROCHEMICALS, 2009. Disponível em: < http:// sitem.herts.ac.uk/aeru/iupac/1154.htm>. Acesso em: 20 abr. 2009.

KARPOZAS, D. G. et al. The effect of initial concentration of carbofuran on the development and stability of its enhanced biodegradation in top- soil and sub-soil. Pest Manag. Sci., v. 57, n. 1, p. 72-81, 2001.

KIMURA, M. A simple method for estimating evolutionary rates of base substitutions through comparative studies of nucleotide sequences. J. Molec. Evol., v. 16, n. 2 , p. 111-120, 1980.

KUMAR, S.; MUKERIJ, K. G.; LAL, R. Molecular aspects of pesticide degradation by microorganisms. Crit. Rev. Microbiol., v. 22, n. 1, p. 1-26, 1996.

LAVORENTI, A. et al. Comportamento do diclosulam em amostras de um Latossolo Vermelho distroférrico sob plantio direto e convencional. R. Bras. Ci. Solo, v. 27, n. 1, p. 183-190, 2003.

LEITE, C. R. F.; ALMEIDA J. C. V.; PRETE C. E. C. Sensibilidade de cultivares de soja (Glycine max) aos diclosulam e flumetsulam. Planta Daninha, v. 18, n. 1, p. 103-122, 2000.
BRASIL. Ministério da Agricultura, Pecuária e

Abastecimento. Companhia Nacional de Abastecimento CONAB. Grãos - Série Histórica de Produção (1976 a 2009). Disponível em: <http://www.conab.gov.br/conabweb/ download/safra/SojaSerieHist.xls>. Acesso em: 11 fev. 2009.

MONTEIRO, R. T. R. Biodegradação de pesticidas em solos brasileiros. In: MELO, I. S. et al. Biodegradação. Jaguariúna: Embrapa Meio Ambiente, 2001. p. 1-28.

NETO, M. E. F. et al. Seletividade de herbicidas pósemergentes aplicados na soja geneticamente modificada Planta Daninha, v. 27, n. 2, p. 345-352, 2009.

RICHARDSON, M. Pesticide - friend or foe? Water Sci. Technol., v. 37, n. 8, p. 19-25, 1998.

RODRIGUES, B. N.; ALMEIDA, F. S. Guia de herbicida Londrina: Iapar, 1998. 648 p.

SCHLEGEL, H. G. General microbiology. 7.ed. New York: 1992. $655 \mathrm{p}$.

SCHRIJVER, A.; MOT, R. Degradation of pesticides by actinomycetes. Crit. Rev. Microbiol., v. 25, n. 2, p. 85-119, 1999.

SILVA, C. M. M. S. O fenômeno da biodegradação acelerada de pesticidas. In: MELO, I. S. et al. Biodegradação. Jaguariúna: Embrapa Meio Ambiente, 2001. p. 15-28.

TIMOSSI, P. C.; DURIGAN, J. C. Manejo de convolvuláceas em dois cultivares de soja semeada diretamente sob palha residual de cana crua. Planta Daninha, v. 24, n. 1, p. 91-98, 2006.

ZABIK J. M. et al. Terrestrial field dissipation of diclosulam at four sites in the United States. J. Agric. Food Chem., v. 49, n. 7, p. 3284-3290, 2001. 